\title{
Morphometry and acetylcholinesterase activity of the myenteric plexus of the wild mouse Calomys callosus
}

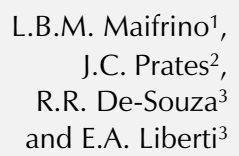

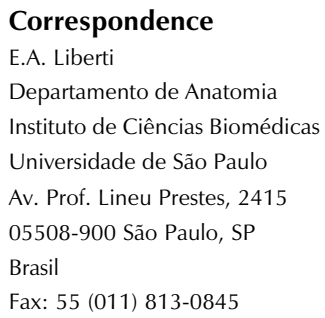

\author{
${ }^{1}$ Instituto Dante Pazzanese de Cardiologia, 04012-180 São Paulo, SP, Brasil \\ ${ }^{2}$ Departamento de Anatomia, Escola Paulista de Medicina, \\ Universidade Federal de São Paulo, 04023-000 São Paulo, SP, Brasil \\ ${ }^{3}$ Departamento de Anatomia, Instituto de Ciências Biomédicas, \\ Universidade de São Paulo, 05508-900 São Paulo, SP, Brasil
}

Abstract

The myenteric plexus of the digestive tract of the wild mouse Calomys callosus was examined using a histochemical method that selectively stains nerve cells, and the acetylcholinesterase (AChE) histochemical technique in whole-mount preparations. Neuronal density was 1,500 \pm 116 neurons $/ \mathrm{cm}^{2}$ (mean $\pm \mathrm{SEM}$ ) in the esophagus, $8,900 \pm 1,518$ in the stomach, 9,000 \pm 711 in the jejunum and 13,100 $\pm 2,089$ in the colon. The difference in neuronal density between the esophagus and other regions was statistically significant. The neuron profile area ranged from 45 to $1,100 \mu \mathrm{m}^{2}$. The difference in nerve cell size between the jejunum and other regions was statistically significant. AChE-positive nerve fibers were distributed within the myenteric plexus which is formed by a primary meshwork of large nerve bundles and a secondary meshwork of finer nerve bundles. Most of the nerve cells displayed AChE activity in the cytoplasm of different reaction intensities. These results are important in order to understand the changes occurring in the myenteric plexus in experimental Chagas' disease.
Key words

- Myenteric plexus

- Wild mouse

- Calomys callosus

- Morphometry

- Histochemistry

\section{Introduction}

Calomys callosus is a wild, native forest rodent commonly found in South America and described in Brazil as harboring Trypanosoma cruzi (1). Laboratory infection of Calomys callosus results in a much lower parasitemia and mortality than seen in mice (2). The rodent is similar to the mouse, except for a shorter tail and grayish brown fur. Size and weight are also comparable to those of mice during the first two months after birth while weight gain is greater from this age on, reaching a maximum weight of about $40 \mathrm{~g}$ (2). Although some aspects of the biology of Calomys callosus have been studied, to our knowledge no information is available concerning the myenteric plexus of this rodent.

In the present investigation we describe the myenteric plexus of the digestive tract of Calomys callosus, demonstrate the presence of acetylcholinesterase activity (AChE), and quantify the number of neurons and the areas of the neuron profiles of the plexus. These data will be used in future investigations on the effects of experimental T. cruzi infection in the myenteric plexus.

\section{Material and Methods}

Seven adult male Calomys callosus 
weighing 30 to $35 \mathrm{~g}$ were used in this study. The animals were sacrificed with an overdose of ether and the following regions of the digestive tract were removed and washed in Krebs solution (3): the distal part of the esophagus and stomach, and portions of the jejunum and distal colon approximately 4 $\mathrm{cm}$ in length.

Each piece was then ligated with cotton thread at both ends and gently distended with Krebs solution introduced with a syringe at one end. When the material was sufficiently distended, the syringe needle was withdrawn and the ligature was simultaneously tightened. After incubation in Krebs solution at room temperature for 15-30 min, the segments were transferred to a permeabilizing agent $(0.3 \%$ Triton-X 100 in Krebs solution) for 15-90 s and then submitted to 3 changes of Krebs solution for a total of about $10 \mathrm{~min}$. The pieces were then incubated for $30-90 \mathrm{~min}$ at $20^{\circ} \mathrm{C}$ in $20 \mathrm{ml}$ incubation medium containing $0.5 \mathrm{mg} / \mathrm{ml}$ nitro blue tetrazolium (Sigma Chemical Co., St. Louis, MO) in distilled water (25 parts), $0.1 \mathrm{M}$ sodium phosphate buffer, $\mathrm{pH} 7.3$ (25 parts), distilled water (50 parts) and $0.5 \mathrm{mg} / \mathrm{ml} 3$-nicotinamide adenine dinucleotide (reduced form) (3).

The development of the reaction was monitored under a dissecting microscope and stopped by immersion of the pieces in $10 \%$ buffered formalin solution in which they were fixed for a minimum of $24 \mathrm{~h}$.

Whole-mounts of the pieces were then prepared as follows: the segments were opened, the mucosa was removed and the longitudinal muscle, with the myenteric plexus attached, was lifted at one corner and gently removed from the entire strip. After several washes in distilled water, three circular fragments $\left(12.56 \mathrm{~mm}^{2}\right)$ were obtained from each portion of the digestive tract, mounted in glycerol on a microscope slide and sealed with Entellan (Merck).

The number of neurons and the profiles of the nerve cells were obtained by examin- ing the circular fragments under a binocular microscope at 400X magnification. All neurons present in the circular fragments were counted. The profiles of 300 nerve cell perikarya for each segment of the digestive tract were outlined on drawing paper using a camera lucida attached to the microscope. The areas of these nerve cell bodies were calculated using a digitizing pad. The data were analyzed statistically using the non-parametric Kruskal-Wallis test (4). For histochemical demonstration of acetylcholinesterase activity, the "direct coloring" copper ferrocyanide method (5) was used in fresh tissues prepared as wholemount stretch preparations.

\section{Results}

\section{Qualitative observations}

The myenteric plexus of the esophagus of Calomys callosus contained small ganglia with elongated or pear-like neurons with an eccentric nucleus, fusiform in profile and scattered throughout the organ (Figure 1A). Large, elongated ganglia with neurons packed in a characteristically tight fashion were observed in the stomach (Figure 1B). In the jejunum and the colon the pattern of the plexus was remarkably regular with long, thin ganglia, the long axes of which laid perpendicular to the circular muscular layer (Figure 1C,D).

The pattern of cholinergic innervation was generally similar in the stomach, jejunum and colon. The histochemical identification of $\mathrm{AChE}$ showed that the myenteric plexus consisted of a primary meshwork of relatively large nerve bundles within which a secondary meshwork of finer nerve bundles was present (Figure 2B-D); the cell bodies occurred in the nodes of the meshwork. Most ganglionic neurons stained intensely for AChE while a few stained only moderately. Some nerve bundles arose from the secondary meshwork of the plexus to form a fine plexus branching throughout both muscle 

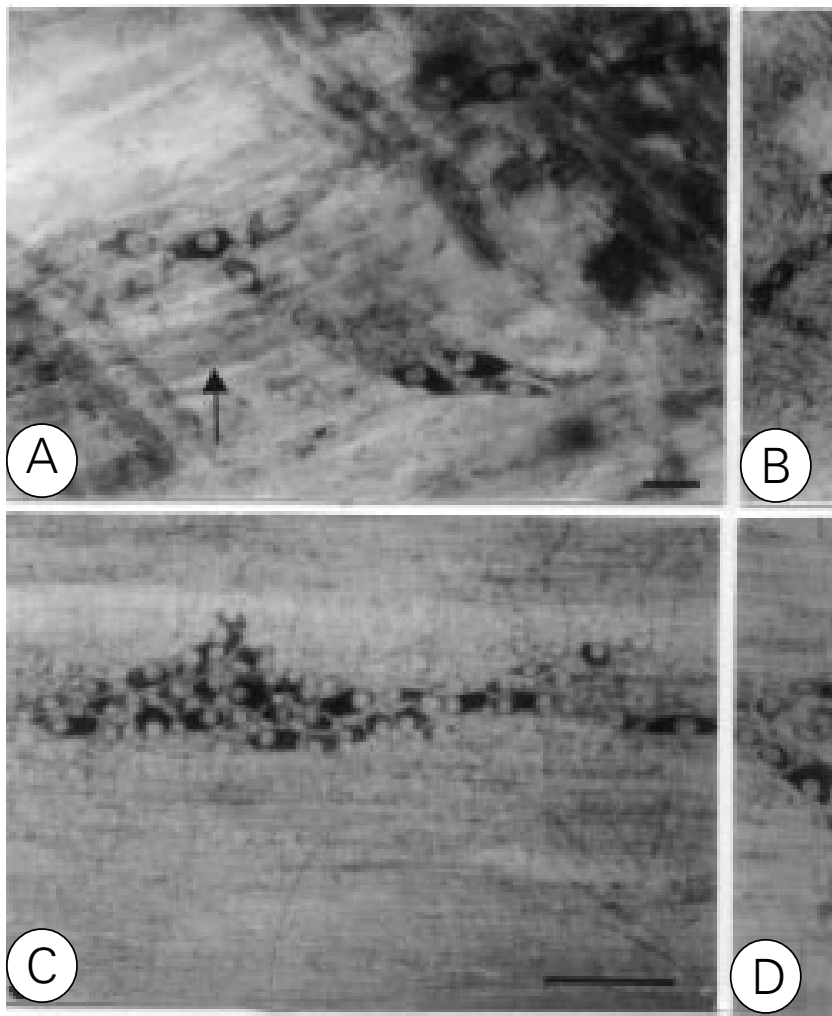

coats. The circular muscle was richly innervated with $\mathrm{AChE}$-stained nerve fibers while the longitudinal muscle layer showed a relatively moderate innervation. The plexus of the esophagus was quite different from those in the stomach and intestine; the neurons showed high AChE activity while the nerve bundles did not stain (Figure 2A).

\section{Quantitative observations}

The spatial density (mean \pm SEM) of neurons is shown in Table 1. Neuronal density was $1,500 \pm 116$ neurons $/ \mathrm{cm}^{2}$ in the esophagus, $8,900 \pm 1,518$ in the stomach, $9,000 \pm 711$ in the jejunum and 13,100 \pm 2,089 in the colon. The difference in neuronal density between the esophagus and the other regions of the digestive tract was statistically significant $(\mathrm{P}<0.05)$.

The maximal cellular profiles (cell sizes) in the digestive tract of Calomys callosus are shown in Table 1. Neuronal sizes ranged from $45 \mu \mathrm{m}^{2}$ to about $1,100 \mu \mathrm{m}^{2}$. The aver- age neuron size was $297 \pm 11 \mu \mathrm{m}^{2}$ in the esophagus, $290 \pm 10 \mu \mathrm{m}^{2}$ in the stomach, $179 \pm 4 \mu^{2}$ in the jejunum and $206 \pm 5 \mu \mathrm{m}^{2}$ in the colon. Statistical analysis indicated that the mean area of the neurons in the jejunum was different from those of the esophagus, stomach and colon; no difference in mean neuron area was observed between the esophagus and stomach. Most neurons had neuron profile areas of $100 \mu \mathrm{m}^{2}$ to $300 \mu \mathrm{m}^{2}$, as shown in Figure 3 .

\section{Discussion}

Wild rodents are natural reservoirs of Trypanosoma cruzi. Mello (6) was the first to study the biology of the wild mouse Calomys callosus, and since then this animal species has been used in experiments with $T$. cruzi $(2,7,8)$. In order to understand the changes occurring in the myenteric plexus in experimental Chagas' disease, information about their detailed structure in the normal state is required.
Figure 1 - Histochemically stained myenteric ganglia from Calomys callosus. $A$, Esophageal ganglia. Note the striated musculature of the esophagus (arrow). $B$, Large ganglion from the stomach. Note the variation in neuronal size. $C$, Large ganglion from the jejunum showing a densely packed cluster of neurons. $D$, Ganglion from the sigmoid colon. Note the variation in the intensity of the reaction among the neurons. Scale bars $=20 \mu \mathrm{m}$. 
Figure 2 - Stretch preparation from the muscle layer of the esophagus (A), stomach (B), jejunum (C) and colon (D) showing the myenteric plexus. Cholinesterase method. A, Intensely stained neurons (arrows). B-D, The plexus consists of a primary meshwork of thick nerve bundles (arrows) and a secondary meshwork of finer bundles (arrowheads). In the primary meshwork, the nerve cell bodies occur mainly at the nodes of the plexus. Note the variable intensity of nerve cell staining. Scale bars $=40 \mu \mathrm{m}$
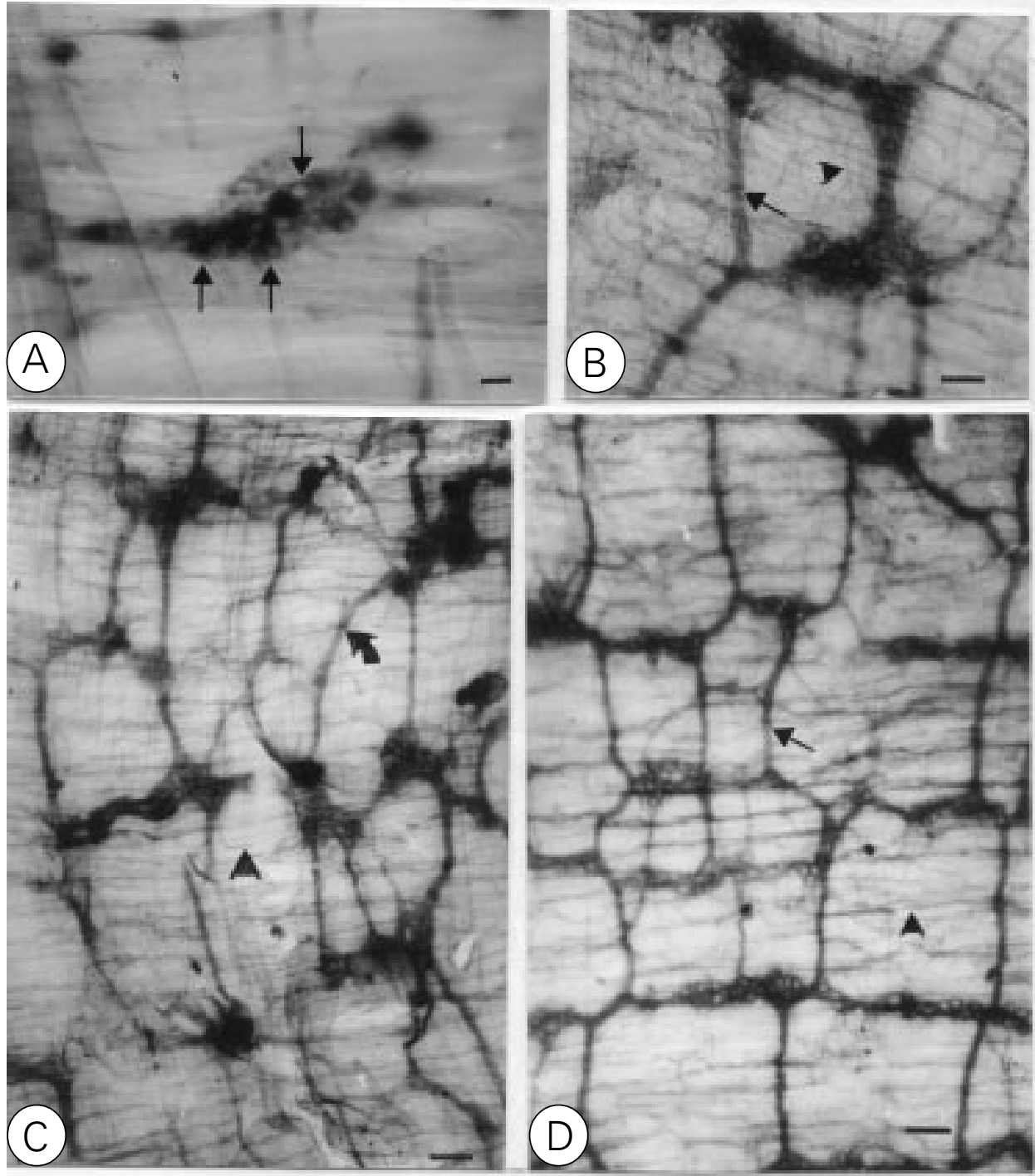

Table 1 - Number and size of myenteric neurons from the digestive tract of Calomys callosus.

Data are reported as mean \pm SEM. The neuron cell profile area was evaluated in 300 nerve cell perikarya for each segment. See Figure 3 for distribution of cell areas. ${ }^{*} \mathrm{P}<0.05$ compared to the other groups.

\begin{tabular}{lcc}
\hline & $\begin{array}{c}\text { Neuron density } \\
\left(\text { per } \mathrm{cm}^{2}\right)\end{array}$ & $\begin{array}{c}\text { Neuron cell profile } \\
\text { area }\left(\mu \mathrm{m}^{2}\right)\end{array}$ \\
\hline Esophagus & $1,500 \pm 116^{*}$ & $297 \pm 11$ \\
Stomach & $8,900 \pm 1,518$ & $290 \pm 10$ \\
Jejunum & $9,000 \pm 711$ & $179 \pm 4$ \\
Colon & $13,100 \pm 2,089$ & $206 \pm 5$
\end{tabular}

The present investigation showed that the nerve cells present in the digestive tract of Calomys callosus are aggregated into ganglia, resembling those observed in other rodents (3). With the exception of the esophagus, the neurons are gathered into long cords which fuse into one another, lacking a clear demarcation into ganglia. In each portion of the digestive tract, the plexus has a characteristic pattern which is reproduced faithfully in different individuals and in different parts of the gut of the same animal, a clear indication of the existence of precise mechanisms regulating the morphogenesis of the 

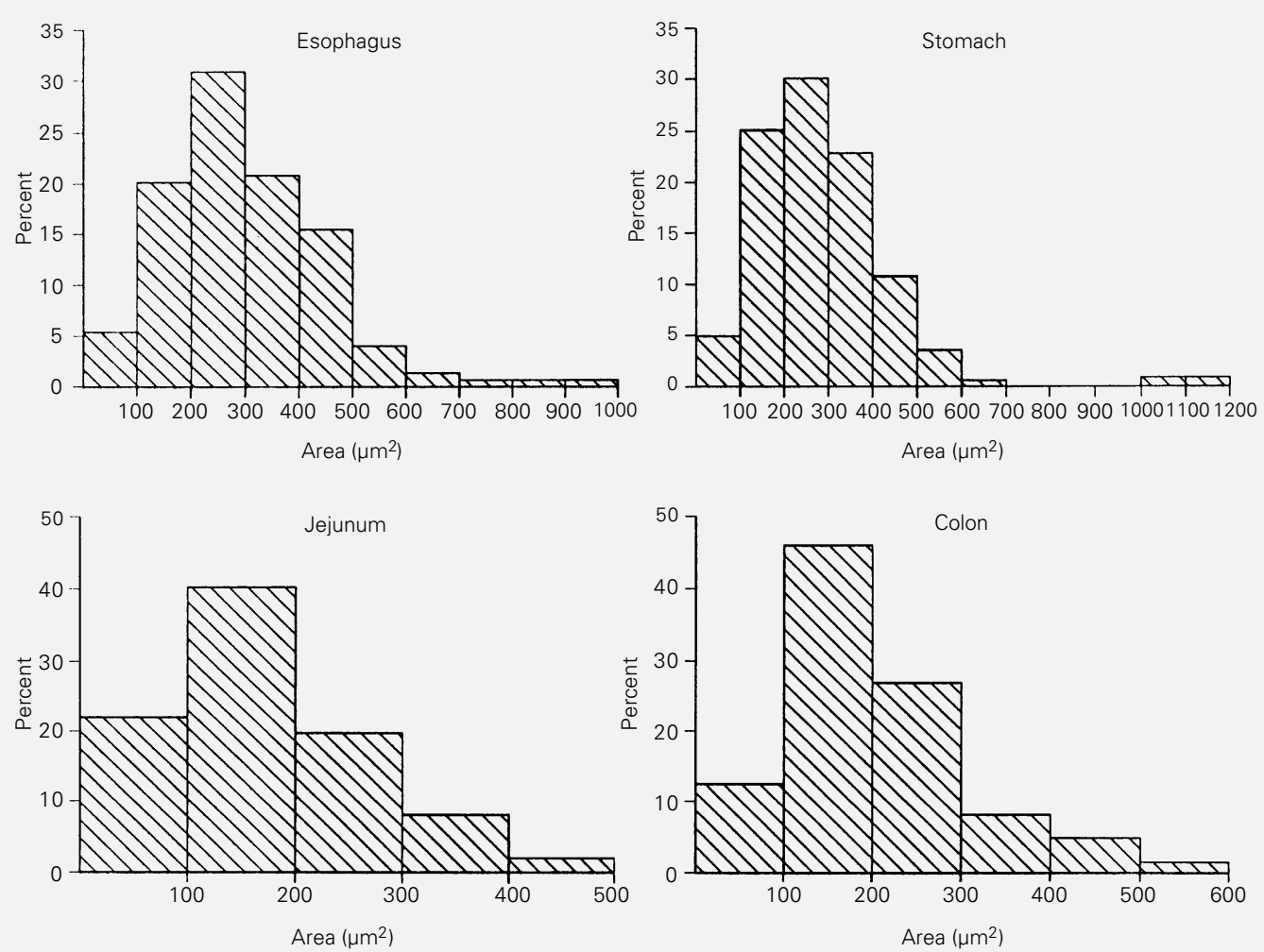

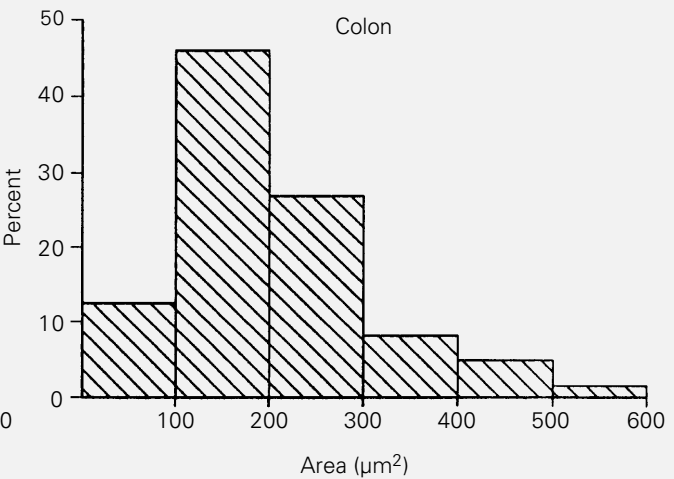

Figure 3 - Distribution of nerve cell profile areas of myenteric neurons from different regions of the gut of Calomys callosus. Most neurons have nerve cell profile areas of $100 \mu \mathrm{m}^{2}$ to $300 \mu \mathrm{m}^{2}$. $\mathrm{N}=300$ cells measured for each region. plexus (3). The pattern of the myenteric plexus in Calomys callosus is not different from that of other rodent species.

The spatial density of the myenteric neurons varied in different parts of the digestive tract of Calomys callosus. The highest average neuronal density was found in the colon (about 13,100 $\pm 2,089$ neurons per $\mathrm{cm}^{2}$ of serosal surface), a value that is substantially lower than the only other measurement available in the literature for the mouse (9). In the esophagus, the neuronal density was about $1,500 \pm 116$ neurons $/ \mathrm{cm}^{2}$ and in the stomach, $8,900 \pm 1,518$. There are no other counts on this species in the literature. A neuronal density similar to that of the esophagus and stomach of Calomys callosus is found in the guinea pig $(10,11)$. The value obtained for the small intestine of Calomys callosus $(9,000$ \pm 711 neurons $/ \mathrm{cm}^{2}$ ) is much lower than that cited for the mouse (9) but similar to that published by Gabella (3).
The size of the myenteric neurons in mice has been investigated in previous studies $(3,12)$. In Calomys callosus, the myenteric perikarya cover a wide range of sizes and this is true for all four portions of the gut. The present study shows that the range of sizes was greater in Calomys callosus than in mice. A population of small neurons was present in all four portions of the digestive tract, while the largest myenteric neurons were larger in the stomach than in the esophagus; and those in the esophagus were larger than those in the jejunum and colon. At present, it is not clear whether the variation in size within the population of myenteric neurons reflects different functional specialization, or differences in the extent of the territory of innervation (13).

Using the acetylcholine method, strong AChE staining was observed within the perikarya of the myenteric plexus in the gastrointestinal tract of Calomys callosus. 
The majority of ganglion neurons stained intensely for AChE. Nerve fibers staining for $\mathrm{AChE}$ were also observed in the longitudinal and circular smooth muscle layers. This finding is in agreement with those reported for the gastrointestinal tracts of several mammalian species $(12,14-16)$. The presence of AChE activity suggests the cholinergic nature of these neurons although AChEpositive neurons need not necessarily be cholinergic since adrenergic and non-cholinergic neurons may also display AChE positivity (17-19). In fact, non-cholinergic functions of $\mathrm{AChE}$ have been demonstrated in the brain; AChE is also present in dopami- nergic nigrostriatal neurons (20). Furthermore, neuronal AChE activity and immunoreactive peptide varicosities have been simultaneously demonstrated in the myenteric plexus (21).

The results of the present study show that the myenteric plexus of the digestive tract of Calomys callosus contains a large number of nerve cells of different sizes and with different AChE activities. These results and the distribution of the cholinesterase-positive fibers in the myenteric plexus of Calomys callosus conform to the general pattern of gastrointestinal innervation demonstrated for mammals, particularly for mice.

\section{References}

1. Ribeiro RD (1973). New reservoir of Trypanosoma cruzi. Revista Brasileira de Biologia, 33: 429-537.

2. Borges MM, Curi PR \& Kloetzel JC (1992). Modulation of parasitemia and antibody response to Trypanosoma cruzi by cyclophosphamide in Calomys callosus (Rodentia, Cricetidae). Revista do Instituto de Medicina Tropical de São Paulo, 34: 1-8.

3. Gabella G (1987). The number of neurons in the small intestine of mice, guinea-pig and sheep. Neuroscience, 22: 737-752.

4. Zar JH (1984). Biostatistical Analysis. Prentice-Hall, New Jersey.

5. Karnowsky MJ \& Roots L (1964). A "direct-coloring" thiocholine method for cholinesterases. Journal of Histochemistry and Cytochemistry, 12: 219-221.

6. Mello DA (1978). Biology of Calomys callosus (Rengger, 1983) under laboratory conditions (Rodentia - Cricetidae). Revista Brasileira de Biologia, 38: 807-811.

7. Mello DA, Valin E \& Teixeira ML (1979). Alguns aspectos do comportamento de cepas silvestres de Trypanosoma cruziem camundongos e Calomys callosus (Rodentia). Revista de Saúde Pública, 13: 314332.

8. Borges MM, Mello DA \& Teixeira ML (1982). Infecção experimental de Calomys callosus (Rodentia - Cricetidae) com Trypanosoma cruzi. Revista de Saúde Pública, 16: 233-242.
9. Tafuri WL \& De Almeida Campos F (1958) Der Auerbach Plexus bei der Maus. Zeitschrift für Naturforschung, 13B: 816819.

10. Matsuo H (1934). A contribution on anatomy of Auerbach's plexus. Japanese Journal of Medical Sciences, 4: 417-428.

11. Ohkubo K (1936). Studien über das intramurale Nervensystem des Verdauungskanals. II. Die Plexus myentericus und Plexus subserosus des Meerschweinchens. Japanese Journal of Medical Sciences, 6: 21-37.

12. Bor-Seng-Shu E, Chadi G, Bor-Jiun-Shu F, Ferraz-de-Carvalho CA \& De-Souza RR (1994). Myenteric neurons of the mouse small intestine. Morphometry and acetylcholinesterase activity. Brazilian Journal of Medical and Biological Research, 27: 101-108.

13. Chiang C \& Gabella G (1986). Quantitative study of the ganglion neurons of the mouse trachea. Cell and Tissue Research, 246: 243-252.

14. Jacobowitz D (1965). Histochemical studies of the autonomic innervation of the gut. Journal of Pharmacology and Experimental Therapeutics, 149: 358-364.

15. Gunn M (1968). Histological and histochemical observations on the myenteric and submucous plexuses of mammals. Journal of Anatomy, 2: 223-239.
16. Wolter HJ (1985). Topography of cholinergic perikarya and nerve fibers as well as cholinergic vesicles in the rat duodenum. Brain Research, 339: 337-341.

17. Eranko O, Rachardt L, Eranko L \& Cunninghan A (1970). Light and electron microscopic histochemical observations on cholinesterase containing sympathetic nerve fibers in the pineal body of the rat. Histochemical Journal, 2: 479-489.

18. Levey Al, Wainer BH, Mufson EJ \& Mesulan MM (1983). Co-localization of acetylcholinesterase and choline acetyltransferase in the rat cerebrum. Neuroscience, 9: 9-22.

19. Seelig LL, Doody P, Brainards L, Gidda JS \& Goyal RK (1984). Acetylcholinesterase and choline acetyltransferase staining of neurons in opossum oesophagus. Anatomical Record, 209: 130-135.

20. Greenfield SA (1985). Acetylcholinesterase release from dendrites. Neuroscience Letters, 22 (Suppl): S3 (Abstract).

21. Anglade P, Michel C, Ozaki T, Tsuji S, Vignon X \& Yanaihara N (1988). Simultaneous localization of acetylcholinesterase activity and met-enkephalin, vasoactive intestinal peptide and substance $\mathrm{P}$ immunoreactivity in the rat myenteric plexus. Histochemical Journal, 20: 464-467. 